\title{
A Randomized Double-Blind Placebo Controlled Clinical Trial Evaluating the Effects of an Investigational Study Product on Exercise Induced Muscle Soreness, Markers of Inflammation, Muscle Damage and Exercise Performance in Healthy Males
}

\author{
Kalman $\mathrm{D}^{1,2}$, Knight $\mathrm{K}^{1}$, Sperry $\mathrm{J}^{1}$, Smith $\mathrm{M}^{1}$, Holms $\mathrm{C}^{1}$, and Hewlings $\mathrm{S}^{\star 2,3}$ \\ ${ }^{1}$ Department of BD, Nutrition and Clinical Research, QPS-BKCA, Springfield, MO, United States \\ ${ }^{2}$ Substantiation Sciences, Weston, FL, United States \\ ${ }^{3}$ Nutrition and Dietetics Department, Central Michigan University, Mt. Pleasant MI, United States
}

${ }^{*}$ Corresponding author: Hewlings S, Nutrition and Dietetics Department, Central Michigan University, Mt. Pleasant MI, United States, Tel: 321-377-4522, E-mail: sue.hewlings@gmail.com

Citation: Kalman D, Knight K, Sperry J, Smith M, Holms C, et al. (2018) A Randomized Double-Blind Placebo Controlled Clinical Trial Evaluating the Effects of an Investigational Study Product on Exercise Induced Muscle Soreness, Markers of Inflammation, Muscle Damage and Exercise Performance in Healthy Males. J Nutr Health Sci 5(1): 104. doi: 10.15744/2393-9060.5.104

Received Date: January 26, 2018 Accepted Date: March 01, 2018 Published Date: March 07, 2018

\begin{abstract}
Gherkin, a pure botanical extract from cucumber is a phytonutrient rich vegetable which may have been shown to have anti-inflammatory and pain relieving properties. The purpose of this randomized double-blind placebo study was to determine the effects of Gherkin $\left(\right.$ Cuvitus $^{\mathrm{m}}$, Actido $\left.{ }^{\circ}\right)$ on exercise performance, markers of inflammation and acute muscle soreness in healthy males. Twenty-four subjects were randomly assigned to take $150 \mathrm{mg}$ Cuvitus $^{\circ}$ or Placebo twice a day for 6 days during the loading phase. Subjects underwent a leg extension protocol designed to induce cellular stress and muscle soreness. Blood was tested pre-exercise, 1 and 2 hours post for TNFalpha, IL-6, IL-10, and IL-1 beta, along with DOMS measurements. The Gherkin group significantly improved exercise performance and ability to maintain output which also strongly trended for significance over placebo. Both groups experienced acute DOMS without differences in values. Taking Cuvitus ${ }^{\otimes} 150 \mathrm{mg}$ twice a day for two weeks lead to better exercise performance when compared to placebo as well as improvements in anti-inflammatory and immune supportive markers.
\end{abstract}

Keywords: Gherkin; Anti-inflammatory; DOMS; Exercise Performance; Pain Relief; Muscle Soreness; Immune Support

\section{Introduction}

Any physical activity that is unfamiliar or that produces an increased load or demand on the muscle can produce delayed onset muscle soreness (DOMS). Eccentric contraction is particularly likely to cause DOMS. Eccentric contraction occurs during activities like downhill running, plyometric movements or the lowering phase of a weight lifting exercise. Exercise-induced muscle soreness is classified into acute and delayed muscle soreness. Acute muscle soreness occurs during the exercise and may continue for about 4 to $6 \mathrm{~h}$. DOMS related soreness occurs 8 to $24 \mathrm{~h}$ after strenuous exercise and typically peaks about 24 to $48 \mathrm{~h}$ after the exercise [1]. The exact mechanisms of DOMS are not completely understood; however, it is generally accepted that it is associated with muscle and/or connective tissue damage and/or related inflammatory responses [2]. It is also known that inflammatory markers and markers of oxidative stress are released [1,3]. It has been proposed that the slow recovery of muscle strength and DOMS are partially due to the action of reactive molecules and/or inflammatory mediators released in the damaged muscle [4-6]. Therefore, addressing the related factors could enhance muscle recovery and therefore benefit exercise performance and related health outcomes. Preventing DOMS and reducing the inflammatory biomarkers is of concern to athletes because the associated symptoms can impair subsequent efforts to train and decrease performance [7]. Therefore, reducing inflammation and preventing DOMS is very desirable to athletes and may allow for longer or more frequent workouts and improved performance. Non-athletes also suffer from this phenomenon as well, potentially leading to impairment in daily activities [7]. Reducing inflammation and DOMS would be desirable in non-athletes as well as athletes and several treatments have been explored for both of these populations [3-8]. Traditionally, these treatments address the inflammatory and oxidative aspects known to associated with 
DOMS and include massage, stretching, and ice therapy, as well as pharmaceutical, nutritional and herbal remedies [3,8]. Many of the prescribed pharmaceutical agents such as nonsteroidal anti-inflammatory medicines (NSAIDs) have unwanted side effects including GI discomfort. Therefore, nutritional and herbal remedies with minimal side effects have gained increasing interest [8]. Despite a lack of evidence to support many recommended treatment strategies, there is evidence that dietary phytochemicals with antioxidant and anti-inflammatory properties can relieve symptoms associated with DOMS [9-11]. One such product is Gherkin, a type of cucumber, a pure botanical extract that has been shown to have anti-inflammatory and pain relieving properties in humans. In vitro studies have demonstrated the presence of flavonoids and tannins in the extract suggesting that the extract may have free radical scavenging and analgesic effects [12]. In-house un-published observational studies have shown a reduction in pain levels and inflammation in athletes supplementing with Gherkin extract for 2-4 weeks. No adverse side effects were reported in any of the observational studies available via in-house data.

The purpose of this study is to determine the effects of a proprietary cucumber extract [active test product (Cucumis sativus L.)] known in the US as Cuvitus ${ }^{\circledast}$ (also known in Europe as Actido ${ }^{\circledR}$ ) on perceived levels of muscle soreness/discomfort after exercise, markers of inflammation, exercise performance, and maintenance of exercise performance.

\section{Materials and Methods}

In a randomized double-blind placebo-controlled design conducted in 2016, 24 healthy male subjects average age of $42.0 \pm 6.7$ years with a mean Body Mass Index (BMI) of $30.0 \pm 3.9 \mathrm{~kg} / \mathrm{m}^{2}$, were randomly assigned to one of the two test groups (active product or placebo). Subjects were included if they were healthy, between $30-65$ years of age, had a BMI of $18-34.99 \mathrm{~kg} / \mathrm{m}^{2}$, in good health, passed the Physical Activity Readiness Questionnaire (PAR-Q) and not using NSAIDS for at least 7 days prior to the study. After receiving a signed informed consent, they were given two capsules per day of $150 \mathrm{mg}$ Cuvitus ${ }^{\circledast}$ (Actido ${ }^{\circledast}$ ), enteric-coated capsule or enteric coated Placebo capsule. They took one capsule in the morning and the second was taken in the evening for six days before the first exercise session. Subjects reported for one screening visit, one familiarization visit, baseline visit (visit 2), and a final test visit (visit 3), all visits were 7 days apart. To control for lifestyle habits (dietary, exercise habits), subjects were asked and monitored to maintain their pre-study normal routines. The familiarization visit was used to determine the subject's one-repetition maximum (1 RM) for the leg extension exercise protocol that would be performed during the test visits. Study participants were asked not to participate in any strenuous exercise for 24 hours prior to the test visits. In addition, they were asked to refrain from consuming alcohol, caffeine or analgesics for 24 hours prior to the test visits. Pre-exercise study procedures for Visits 2 and 3 consisted of: Visual Analog Scales (VAS) (pain/discomfort pre-exercise), vital signs monitoring, and pre-dose blood collection for TNF-alpha, IL-6, IL-10, IL-1 beta. The VAS was used to assess the discomfort caused by the exercise protocol for inducing muscle damage and soreness (exercise performed at Visits 2 and 3. Subjects rated their feelings of discomfort on a 10-point scale with higher scores indicating more discomfort. The rating was performed pre-exercise (prior to the leg-extension protocol for inducing muscle damage) and post-exercise at approximately 1 and 2 hours (following the leg-extension protocol for inducing muscle damage). Subjects then took one dose (150mg) of either Active or Inactive Test Product one hour before performing the exercise protocol to induce DOMS. To control for dietary intake on test days, subjects were provided with a standardized meal and snacks. The study (Protocol No. 52816) dated 16 November 2016 and the informed consent form (ICF) dated 21 November 2016 were approved by the QPS Bio-Kinetic Clinical Applications, LLC Institutional Review Board (IRB) on 21 November 2016.

Exercise protocol to induce DOMS and measure exercise performance consisted of:

- Step 1: 5 sets of 10 reps at 30\% estimated 1-RM (50 reps total), 3 min rest

- Step 2: 5 sets of 10 reps at 45\% estimated 1-RM (50 reps total), 3 min rest

- Step 3: 5 sets of 10 reps at 60\% estimated 1-RM (50 reps total), 15-20 min rest

- Step 4 (Set 1): 1 set of reps to failure at 70\% 1-RM, 3 min rest

- The number of repetitions performed was counted and documented

- Step 5 (Set 2): Exact repeat of Step 4

- Step 6 (Set 3): Exact repeat of Step 4

- The number of repetitions to failure from Steps 4, 5, and 6 were totaled

Scoring: Total Work Capacity=Total \# of Repetitions (cumulative repetitions from Steps 4, 5 and 6, also known as Sets 1, 2 and 3 also stated as Set $1+$ Set $2+$ Set $3=$ TWC). Total Work Capacity is also denoted as repetitions performed multiplied by the weight used to determine total pounds lifted.

Scoring: Performance Maintenance=The ability to maintain exercise performance set to set, over the three test sets (Set 1,2,3) was also measured. This was analyzed as evaluated as measuring the set to set performance per test visit and over time.

\section{Statistical Methods}

Statistical software utilized for this study included SAS ${ }^{\varpi}$ v9.4, 2016. (SAS Institute Inc, Cary, NC, USA) and Microsoft Excel 2003 (Microsoft Corp, Redmond WA). All statistical analyses were conducted at the 0.05 alpha level ( $\mathrm{p} \leq 0.05$ was considered nominally significant). Changes in quantitative (numerical) safety endpoints (standard blood tests, changes in vital signs (blood pressure or heart rate), subjective statements within each product) were tested for significance by the paired Student t-test. The efficacy 
endpoints on study products and time point were calculated using repeated-measures analysis of variance (RMANOVA).

\section{Results}

There were no adverse events reported by any subject after receiving study product during this study. Study staff also observed subjects for any potential adverse events and none were observed. There were no differences between groups at baseline for age, body mass index, vital signs (i.e., blood pressure) and organ functions (liver, kidney, glucose and other markers), or other clinical markers (Table 1).

\begin{tabular}{|c|c|c|c|c|c|c|}
\hline Variable & Statistic & $\begin{array}{l}\text { Active Product } \\
\qquad(\mathrm{N}=12)\end{array}$ & $\begin{array}{l}\text { Placebo } \\
(\mathrm{N}=12)\end{array}$ & P-value & $\begin{array}{l}\text { Total Subjects } \\
\quad(\mathrm{N}=\mathbf{2 4})\end{array}$ & $\begin{array}{c}\text { Reference } \\
\text { Range }\end{array}$ \\
\hline $\begin{array}{c}\text { Age } \\
\text { (years) }\end{array}$ & $\begin{array}{l}\text { Mean } \pm \text { SD } \\
\text { Median } \\
\text { (Min-Max) }\end{array}$ & $\begin{array}{c}41.9 \pm 6.3 \\
43.5 \\
(30.0-55.0)\end{array}$ & $\begin{array}{c}42.2 \pm 7.3 \\
43.0 \\
(30.0-55.0)\end{array}$ & 0.9162 & $\begin{array}{c}42.0 \pm 6.7 \\
43.5 \\
(30.0-55.0)\end{array}$ & $30-65$ \\
\hline $\begin{array}{l}\text { Height } \\
(\mathrm{cm})\end{array}$ & $\begin{array}{l}\text { Mean } \pm \text { SD } \\
\text { Median } \\
\text { (Min-Max) }\end{array}$ & $\begin{array}{c}176.5 \pm 7.0 \\
176.5 \\
(166.0-188.0) \\
\end{array}$ & $\begin{array}{c}175.3 \pm 6.6 \\
174.5 \\
(165.0-190.0) \\
\end{array}$ & 0.6511 & $\begin{array}{c}175.9 \pm 6.7 \\
175.0 \\
(165.0-190.0) \\
\end{array}$ & \\
\hline $\begin{array}{l}\text { Weight } \\
(\mathrm{kg})\end{array}$ & $\begin{array}{l}\text { Mean } \pm \text { SD } \\
\text { Median } \\
\text { (Min-Max) }\end{array}$ & $\begin{array}{c}91.9 \pm 13.1 \\
90.8 \\
(73.6-117.3)\end{array}$ & $\begin{array}{c}93.8 \pm 17.1 \\
95.5 \\
(65.4-126.0)\end{array}$ & 0.7903 & $\begin{array}{c}92.9 \pm 14.9 \\
92.4 \\
(65.4-126.0)\end{array}$ & \\
\hline $\begin{array}{l}\text { Body Mass Index (BMI) } \\
\qquad\left(\mathrm{kg} / \mathrm{m}^{2}\right)\end{array}$ & $\begin{array}{l}\text { Mean } \pm \text { SD } \\
\text { Median } \\
\text { (Min-Max) }\end{array}$ & $\begin{array}{c}29.5 \pm 3.86 \\
30.1 \\
(24.2-34.3)\end{array}$ & $\begin{array}{c}30.4 \pm 4.0 \\
31.2 \\
(22.4-34.9)\end{array}$ & 0.6609 & $\begin{array}{c}30.0 \pm 3.9 \\
31.0 \\
(22.4-34.9)\end{array}$ & $\begin{array}{l}18.00 \text { to } \\
34.99\end{array}$ \\
\hline $\begin{array}{l}\text { Systolic BP } \\
\text { (mm Hg) }\end{array}$ & $\begin{array}{l}\text { Mean } \pm \text { SD } \\
\text { Median } \\
\text { (Min-Max) }\end{array}$ & $\begin{array}{c}127.9 \pm 12.2 \\
126.5 \\
(109.0-148.0) \\
\end{array}$ & $\begin{array}{c}123.4 \pm 11.0 \\
124.5 \\
(106.0-140.0) \\
\end{array}$ & 0.3500 & $\begin{array}{c}125.7 \pm 11.6 \\
124.5 \\
(106.0-148.0) \\
\end{array}$ & \\
\hline $\begin{array}{l}\text { Diastolic BP } \\
(\mathbf{m m ~ H g})\end{array}$ & $\begin{array}{l}\text { Mean } \pm \text { SD } \\
\text { Median } \\
\text { (Min-Max) }\end{array}$ & $\begin{array}{c}82.8 \pm 4.0 \\
84.0 \\
(76.0-89.0)\end{array}$ & $\begin{array}{c}81.4 \pm 8.1 \\
81.5 \\
(65.0-90.0)\end{array}$ & 0.5848 & $\begin{array}{c}82.1 \pm 6.3 \\
83.0 \\
(65.0-90.0) \\
\end{array}$ & \\
\hline $\begin{array}{c}\text { Heart Rate } \\
\text { (beats/minute) }\end{array}$ & $\begin{array}{l}\text { Mean } \pm \text { SD } \\
\text { Median } \\
\text { (Min-Max) }\end{array}$ & $\begin{array}{c}73.1 \pm 14.6 \\
72.5 \\
(52.0-102.0)\end{array}$ & $\begin{array}{c}72.6 \pm 12.3 \\
71.5 \\
(50.0-99.0)\end{array}$ & 0.9369 & $\begin{array}{c}72.8 \pm 13.2 \\
72.0 \\
(50.0-102.0) \\
\end{array}$ & \\
\hline $\begin{array}{c}\text { Hemoglobin }(\mathrm{Hgb}) \\
(\mathrm{g} / \mathrm{dL})\end{array}$ & $\begin{array}{l}\text { Mean } \pm \text { SD } \\
\text { Median } \\
\text { (Min-Max) }\end{array}$ & $\begin{array}{c}15.6 \pm 0.77 \\
15.6 \\
(14.3-16.7) \\
\end{array}$ & $\begin{array}{c}15.2 \pm 1.2 \\
15.3 \\
(13.2-16.8)\end{array}$ & 0.2438 & $\begin{array}{c}15.4 \pm 1.0 \\
15.5 \\
(13.2-16.8) \\
\end{array}$ & $\begin{array}{c}(\geq 19 y) \\
13.2-17.1\end{array}$ \\
\hline $\begin{array}{l}\text { Hematocrit (Hct) } \\
(\%)\end{array}$ & $\begin{array}{l}\text { Mean } \pm \text { SD } \\
\text { Median } \\
\text { (Min-Max) }\end{array}$ & $\begin{array}{c}46.4 \pm 2.0 \\
46.4 \\
(43.0-50.2) \\
\end{array}$ & $\begin{array}{c}45.2 \pm 3.0 \\
45.6 \\
(39.2-49.5) \\
\end{array}$ & 0.1964 & $\begin{array}{c}45.8 \pm 2.6 \\
45.9 \\
(39.2-50.2) \\
\end{array}$ & $\begin{array}{c}(\geq 19 y) \\
38.5-50.0\end{array}$ \\
\hline $\begin{array}{l}\text { White Cell Count (WBC) } \\
\text { (Thousand } / \mathbf{m m}^{3)}\end{array}$ & $\begin{array}{l}\text { Mean } \pm \text { SD } \\
\text { Median } \\
\text { (Min-Max) }\end{array}$ & $\begin{array}{c}6.7 \pm 1.5 \\
7.2 \\
(3.5-8.4)\end{array}$ & $\begin{array}{c}8.0 \pm 1.7 \\
7.5 \\
(5.8-12.2)\end{array}$ & 0.0626 & $\begin{array}{c}7.3 \pm 1.7 \\
7.5 \\
(3.5-12.2)\end{array}$ & $\begin{array}{c}(\geq 19 y) \\
3.8-10.8\end{array}$ \\
\hline $\begin{array}{l}\text { Red Cell Count (RBC) } \\
\quad\left(\text { Million/mm } \mathbf{m m}^{3)}\right.\end{array}$ & $\begin{array}{l}\text { Mean } \pm \text { SD } \\
\text { Median } \\
\text { (Min-Max) }\end{array}$ & $\begin{array}{c}5.2 \pm 0.3 \\
5.1 \\
(4.8-5.7) \\
\end{array}$ & $\begin{array}{c}5.5 \pm 1.3 \\
5.2 \\
(4.5-9.4) \\
\end{array}$ & 0.4310 & $\begin{array}{c}5.4 \pm 0.9 \\
5.2 \\
(4.5-9.4)\end{array}$ & $\begin{array}{l}(\geq 19 \mathrm{y}) \\
4.2-5.8\end{array}$ \\
\hline $\begin{array}{c}\text { BUN } \\
(\mathbf{m g} / \mathbf{d L})\end{array}$ & $\begin{array}{l}\text { Mean } \pm \text { SD } \\
\text { Median } \\
\text { (Min-Max) }\end{array}$ & $\begin{array}{c}15.1 \pm 4.6 \\
15.5 \\
(7.0-23.0)\end{array}$ & $\begin{array}{c}12.2 \pm 4.6 \\
13.0 \\
(1.5-21.0)\end{array}$ & 0.1677 & $\begin{array}{c}13.6 \pm 4.8 \\
14.0 \\
(1.5-23.0)\end{array}$ & $7.0-18.0$ \\
\hline $\begin{array}{l}\text { Creatinine } \\
(\mathrm{mg} / \mathrm{dL})\end{array}$ & $\begin{array}{l}\text { Mean } \pm \text { SD } \\
\text { Median } \\
\text { (Min-Max) }\end{array}$ & $\begin{array}{c}1.0 \pm 0.1 \\
1.0 \\
(0.9-1.2)\end{array}$ & $\begin{array}{c}1.0 \pm 0.1 \\
1.0 \\
(0.8-1.3)\end{array}$ & 0.9048 & $\begin{array}{c}1.0 \pm 0.1 \\
1.0 \\
(0.8-1.3)\end{array}$ & $0.70-1.30$ \\
\hline $\begin{array}{l}\text { Alk Phos } \\
\text { (U/L) }\end{array}$ & $\begin{array}{c}\text { Mean } \pm \text { SD } \\
\text { Median } \\
\text { (Min-Max) }\end{array}$ & $\begin{array}{c}63.7 \pm 11.3 \\
65.0 \\
(36.0-82.0) \\
\end{array}$ & $\begin{array}{c}66.8 \pm 14.1 \\
66.0 \\
(41.0-89.0) \\
\end{array}$ & 0.5738 & $\begin{array}{c}65.3 \pm 12.6 \\
65.0 \\
(36.0-89.0) \\
\end{array}$ & $45-117$ \\
\hline $\begin{array}{l}\text { ALT } \\
(\mathrm{U} / \mathrm{L})\end{array}$ & $\begin{array}{c}\text { Mean } \pm \text { SD } \\
\text { Median } \\
\text { (Min-Max) }\end{array}$ & $\begin{array}{c}34.0 \pm 13.9 \\
31.0 \\
(18.0-69.0) \\
\end{array}$ & $\begin{array}{c}37.3 \pm 17.7 \\
29.5 \\
(18.0-72.0) \\
\end{array}$ & 0.5600 & $\begin{array}{c}35.6 \pm 15.7 \\
29.5 \\
(18.0-72.0 \\
\end{array}$ & $13-61$ \\
\hline $\begin{array}{l}\text { AST } \\
(\mathrm{U} / \mathrm{L})\end{array}$ & $\begin{array}{c}\text { Mean } \pm \text { SD } \\
\text { Median } \\
\text { (Min-Max) }\end{array}$ & $\begin{array}{c}23.3 \pm 8.6 \\
22.0 \\
(8.0-42.0) \\
\end{array}$ & $\begin{array}{c}20.8 \pm 5.8 \\
20.5 \\
(13.0-29.0) \\
\end{array}$ & 0.4491 & $\begin{array}{c}22.0 \pm 7.3 \\
22.0 \\
(8.0-42.0) \\
\end{array}$ & $15-37$ \\
\hline $\begin{array}{l}\text { Glucose } \\
(\mathrm{mg} / \mathrm{dL})\end{array}$ & $\begin{array}{l}\text { Mean } \pm \text { SD } \\
\text { Median } \\
\text { (Min-Max) }\end{array}$ & $\begin{array}{c}87.1 \pm 6.2 \\
86.0 \\
(79.0-100.0)\end{array}$ & $\begin{array}{c}86.3 \pm 5.5 \\
86.0 \\
(79.0-98.0)\end{array}$ & 0.7160 & $\begin{array}{c}86.7 \pm 5.7 \\
86.0 \\
(79.0-100.0)\end{array}$ & 74-106 \\
\hline
\end{tabular}

Table 1: Baseline Characteristics of Subjects in the Safety Population

Statistical analysis for heterogeneity included the use of the Paired t-test. 
There were significant $(\mathrm{p}<.05)$ changes in TNF alpha within groups for both placebo and the Gherkin extract group, but no significant between-group differences. For the Gherkin extract group, TNF alpha went from a baseline of $4.2 \pm 11.7 \mathrm{pg} / \mathrm{ml}$ to $4.6 \pm 13.0 \mathrm{pg} / \mathrm{ml}$ and then $3.3 \pm 10.2 \mathrm{pg} / \mathrm{ml}$ from pre-exercise to 1 and 2 hours post-exercise respectively, whereas the Placebo group experienced $1.3 \mathrm{pg} / \mathrm{ml}, 0.9 \mathrm{pg} / \mathrm{ml}$ and $1.8 \mathrm{pg} / \mathrm{ml}$ respectively for the same time points.

There were significant improvements and enhanced recovery of IL-6 within group for each group with improvements trending toward being significantly greater in the Gherkin extract group compared to placebo $(1.6 \pm 1.6 \mathrm{vs} 2.9 \pm 2.8 ; \mathrm{p}=0.0581)$ at the 2 -hour post-exercise time-point. The Gherkin extract group experienced a baseline of $1.1 \pm 1.5 \mathrm{pg} / \mathrm{ml}$, with 1 and 2-hour scores of $2.4 \pm 3.6$ $\mathrm{pg} / \mathrm{ml}$ and $1.6 \pm 1.6 \mathrm{pg} / \mathrm{ml}$, while the Placebo scores were $1.8 \pm 2.5 \mathrm{pg} / \mathrm{ml}$, to 1-hour $3.6 \pm 8.6 \mathrm{pg} / \mathrm{ml}$ and 2-hours $2.9 \pm 2.8 \mathrm{pg} / \mathrm{ml}$.

There were significant changes in IL-10 within each group (consistent with the exercise stressor that was employed). The Gherkin extract group had baseline levels of $1.3 \pm 0.7 \mathrm{pg} / \mathrm{ml}$ which then at 1 -hour was $1.5 \pm 0.9 \mathrm{pg} / \mathrm{ml}$ before returning to $1.3 \pm 0.7 \mathrm{pg} / \mathrm{ml}$ at the 2-hour mark, whereas Placebo group started at $1.8 \pm 2.1 \mathrm{pg} / \mathrm{ml}$ and went to $1.5 \pm 1.0 \mathrm{pg} / \mathrm{ml}$ at the 1 -hour mark and $1.7 \pm 1.5 \mathrm{pg} / \mathrm{ml}$ at the 2-hour mark. The change from the 1 hour to the 2 - hour mark post-exercise demonstrated significant improvement (recovery) in the Gherkin extract group as compared to the Placebo group ( $0.25 \pm 0.49$ vs $-0.2 \pm 0.9 \mathrm{pg} / \mathrm{ml} ; \mathrm{S} .0423)$.

The rise in IL-1 beta 2-hours post-exercise trended towards being significantly greater in the placebo compared to the treatment $(0 \pm 0$ vs $0.01 \pm 0.03 \mathrm{pg} / \mathrm{ml} ; \mathrm{p}=0.058)$. There were no differences between the groups at any other study time point.

For exercise performance measurements (work capacity), at Visit 2 the Gherkin extract group performed 15.0 \pm 7.5 total repetitions, whereas Placebo group performed 20.1 \pm 9.2 total repetitions. At Visit 3, the Gherkin extract group improved their performance to those on the Gherkin extract group improved their total repetitions performed to 21.4 \pm 9.4 , while the Placebo group stayed about the same 21.4 \pm 9.7 repetitions. The change from test visit 2 to test visit 3 for total repetitions lifted (work performed) trended for significance for the Gherkin extract group over the placebo group ( $-6.4 \pm 6.9$ vs $-1.3 \pm 7.6 ; p=0.101$.

For exercise performance measurements (work capacity), at Visit 2 the Gherkin extract group performed 15.0 \pm 7.5 total repetitions, whereas Placebo group performed 20.1 \pm 9.2 total repetitions. At Visit 3, the Gherkin extract group improved their performance to those on the Gherkin extract group improved their total repetitions performed to 21.4 \pm 9.4 , while the Placebo group stayed about the same 21.4 \pm 9.7 repetitions. The change from test visit 2 to test visit 3 for total repetitions lifted (work performed) trended for significance for the Gherkin extract group over the placebo group ( $-6.4 \pm 6.9$ vs $-1.3 \pm 7.6 ; \mathrm{p}=0.101)$.

Examining the effect on work capacit, the Gherkin extract group experienced a significant improvement in the ability to do work (amount of weight lifted), with a 753.55 $\pm 845.74 ; \mathrm{p}=0.0144$ pound improvement from Visit 2 to Visit 3, compared to 121.58 \pm 922.36 ; $\mathrm{p}=0.6568$ pound improvement in work for the placebo group (Table 2). This illustrates that the Gherkin extract group improved their strength and overall muscular endurance $(\mathrm{p}=0.0144)$, while also trending for significance over the Placebo group $(\mathrm{p}=0.1012)$.

\begin{tabular}{|c|c|c|c|}
\hline Time Point & Gherkin extract (pounds) & Placebo (pounds) & P-Value \\
\hline Visit 2 & $1821.45 \pm 942.81$ & $2262.17 \pm 1027.59$ & 0.2956 \\
& $1440.00(411.00-3124.00)$ & $1908.00(1595.00-5175.00)$ & 0.6755 \\
\hline Visit 3 & $2575.00 \pm 1056.39$ & $2383.75 \pm 1103.48$ & \\
\hline Change from Visit 3 to & $2550.00(959.00-3900.00)$ & $2397.50(580.00-4350.00)$ & 0.1012 \\
Visit 2 & $\begin{array}{c}753.55 \pm 845.74 \\
(-340.00-2600)\end{array}$ & $\begin{array}{c}121.58 \pm 922.36 \\
(-1265.00-1740.00) \\
\mathrm{p}=0.6568\end{array}$ & \\
\hline
\end{tabular}

Table 2: Mean Plot for Total Workload

Delayed onset muscle soreness (DOMS) was significantly greater post-exercise compared to pre-exercise in both groups. The Gherkin extract group started pre-exercise with a score of $1.4 \pm 0.8$, rising to $4.7 \pm 2.4$ at 1-hour and reducing to $4.2 \pm 2.2$ by hour 2 post-exercise. The Placebo group started at 1.8 \pm 2.0 , rising to a score of $4.1 \pm 2.5$ at 1-hour and 3.5 \pm 3.5 at the 2-hour time point. There was no significant difference between the groups at any time point for DOMS rating, indicating both groups experienced similar changes in perceived acute muscle soreness.

\section{Discussion}

To our knowledge this is the first study to examine the effects of a proprietary cucumber extract (active test product $150 \mathrm{mg}$ Gherkin (Cucumis sativus L.) (the tradenames Cuvitus ${ }^{\circ}$ and Actido ${ }^{\circ}$ are interchangeable as brands of the proprietary Gherkin extract) acute markers of inflammation; exercise performance and on ability to maintain exercise performance on perceived levels of muscle soreness acutely after exercise. There were no adverse reactions, nor observed adverse events, supporting the safety of the product established in previous studies as shared by the Sponsor's in-house pre-clinical studies. In their first observational study, Gherkin extract was analyzed and confirmed as free of banned substances establishing that it can be safely used by competing athletes (in house data). Twenty top athletes in various track and field disciplines were followed for a year in an observational study; $65 \%$ of the subjects reported a "reduction in pain level" associated with acute or chronic levels of inflammation. In a second observational study on active adults, $80 \%$ of the participants reported a reduction in discomfort/pain and no negative or untoward. 
In the current study, the group taking the Gherkin extract experienced significant changes in cytokines, from pre-exercise intervention to the acute post-exercise time period. The exercise intervention is considered very stressful and is of the anaerobic nature (overall high volume of leg extensions performed). These exercises and volume of exercise are known to induce oxidative stress, disrupt cellular membranes and induce muscular and cellular damage associated with DOMS. In this study, both groups experienced significant changes in DOMS from pre-exercise, indicating that both groups experienced approximately the same perceived levels of muscle soreness and reconfirms that the exercise intervention chosen is successful at inducing muscle soreness.

The Gherkin extract group experienced significant changes within group with respect to Tumor Necrosis Factor - alpha (an inflammatory cytokine that helps regulate immune cells). Significant within group changes were observed for both groups for IL-6, an anti-inflammatory myokine. The differences between the groups trended strongly for significance favoring the Gherkin extract group for improved and enhanced recovery of the IL-6 cytokine. A study by Trombold, et al. noted no difference in IL- 6 over 96 hours post-exercise in active males taking a placebo or a pomegranate extract for 9 days before undergoing eccentric elbow flexion to induce DOMS [13]. Interleukin-10 (IL-10) is an anti-inflammatory cytokine and has emerged as a key immunoregulator during infection with viruses, bacteria, fungi, protozoa, and from helminths. There were significant changes in IL-10 within each group (consistent with the exercise stressor that was employed). The change from the 1 hour to the 2-hour mark post-exercise demonstrated significant improvement (recovery) in the Gherkin extract group as compared to the Placebo group ( $\mathrm{p}=0.0423$ ). Interleukin-10 (IL-10) is an anti-inflammatory cytokine and has emerged as a key immunoregulator during infection with viruses, bacteria, fungi, protozoa, and from helminths. This indicates the potential enhanced cellular recovery effect of Gherkin extract. IL-1beta is an important mediator of the inflammatory response, and is involved in a variety of cellular activities, including cell proliferation, differentiation, and apoptosis. IL-1beta is ultimately produced by monocytes (macrophages, part of the immune system) and helps regulate the inflammatory response in the body. Elevated or rising IL-1beta activity is an indicator that the body is building an inflammatory response, and more specifically, since IL-1beta activity is also related to the activity of cyclooxygenase II (COX-II), it is also found to play a role in the sensitivity to pain.

The treatment resulted in a $~ 6.2$ times improvement in exercise performance (work capacity) over placebo, this significant withingroup change and significant between-group finding is of interest and is worthy of further follow-up research. Similarly, a study by Clifford, et al. reported enhanced improvements in exercise performance and decreased muscle soreness but no changes in cytokines after acute supplementation with beet root juice compared to placebo in recreationally exercisers after performing a DOMS inducing exercise protocol [14]. Connolly, et al. reported an improvement in exercise performance and pain in male college students consuming 12 ounces of tart cherry juice compared to placebo after performing eccentric elbow flexion contractions. Strength loss averaged over the four days after eccentric exercise was $22 \%$ with the placebo but only $4 \%$ with the cherry juice [10]. While these studies were conducted utilizing different phytochemicals than used in our study, they offer support for the benefits of various phytochemicals in improving symptoms and performance detriments associated with DOMS. In addition to improvements in exercise performance, the Gherkin extract group significantly improved the subjects' ability to do work (amount of weight lifted), from Visit 2 to Visit 3.

In general, this early stage study of Gherkin extract in exercising individuals pointed to an effect on inflammatory cytokines as well as exercise performance, viewed both as work performed and for the ability to maintain exercise performance over multiple sets. These novel findings indicate that larger trials are needed to further determine how this vegetable extract may play a nutritional support role for the athlete during hard training periods.

A limitation of this study was that we measured acute DOMS (within hours of completing the exercise test sessions), versus the more typical days of DOMS (24 to 96 hours, with most 48 to 72 hours after exercise intervention). This shorter measurement period may not have allowed enough time after the exercise intervention to determine if the Gherkin extract had any effect over placebo on perceived delayed onset muscle soreness. Therefore, it is recommended for future studies assessing the effects of the Gherkin extract on recovery to examine DOMS for a longer period of time post exercise.

\section{Acknowledgment}

The researchers would like to thank the study participants for their participation in the study and the staff at QPS for conducting the study. Substantiation Sciences for medical writing, presentation and publication. The study was funded by XSTO Solutions and Naturelea, SA.

\section{Author Contributions}

Douglas Kalman study design, study report and editing; Katelin Knight - Research Coordinator; Joan Sperry - Research Coordinator; Mark Smith - Study PI, Study Physician; Cassandra Holds - Research Coordinator; Susan Hewlings - writing manuscript, corresponding author.

\section{References}

1. Connolly DAJ, Sayers SE, McHugh MP (2003) Treatment and prevention of delayed onset muscle soreness. J Strength Cond Res 17: 197-208.

2. Cheung K, Hume PA, Maxwell L (2003) Delayed onset muscle soreness: treatment strategies and performance factors. Sports Med. 33: 145-64.

3. Kim J, Lee J (2014) A review of nutritional intervention on delayed onset muscle soreness. Part I. J Exerc Rehabil 10: 349-56. 
4. MacIntyre DL, Reid WD, Lyster DM, Szasz IJ, McKenzie DC (1996) Presence of WBC, decreased strength, and delayed soreness in muscle after eccentric exercise. J Appl Physiol 80: 1006-13.

5. Malm C, Sjödin TL, Sjöberg B, Lenkei R, Renström P, et al. (2004) Leukocytes, cytokines, growth factors and hormones in human skeletal muscle and blood after uphill or downhill running. J Physiol 556: 983-1000.

6. Butterfield TA, Best TM, Merrick MA (2006) The dual roles of neutrophils and macrophages in inflammation: a critical balance between tissue damage and repair. J Athl Train 41: 457-65.

7. Chen TC, Nosaka K, Tu JH (2007) Changes in running economy following downhill running. J Sports Sci 25: 55-63.

8. Meamarbashi A (2017) Herbs and natural supplements in the prevention and treatment of delayed-onset muscle soreness. Avicenna J Phytomed 7: 16-26.

9. McLeay Y, Barnes MJ, Mundel T, Hurst SM, Hurst RD, et al. (2012) Effect of New Zealand blueberry consumption on recovery from eccentric exercise-induced muscle damage. J Int Soc Sports Nutr 9: 19.

10. Connolly DA, McHugh MP, Padilla-Zakour OI, Carlson L, Sayers SP (2006) Efficacy of a tart cherry juice blend in preventing the symptoms of muscle damage. Br J Sports Med. 40: 679-83.

11. Pereira Panza VS, Diefenthaeler F, da Silva EL (2015) Benefits of dietary phytochemical supplementation on eccentric exercise-induced muscle damage: is including antioxidants enough? Nutrition 31: 1072-82.

12. Kumar D, Kumar S, Singh J, Narender, Rashmi, et al. (2010) Free Radical Scavenging and Analgesic Activities of Cucumis sativus L. Fruit Extract. J Young Pharm 2: 365-8

13. Trombold JR, Barnes JN, Critchley L, Coyle EF (2010) Ellagitannin consumption improves strength recovery 2-3 d after eccentric exercise. Med Sci Sports Exerc 42: 493-8.

14. Clifford T, Bell O, West DJ, Howatson G, Stevenson EJ, et al. (2016) Antioxidant-rich beetroot juice does not adversely affect acute neuromuscular adaptation following eccentric exercise. J Sports Sci 7: 1-8. 